\title{
EL DISPAR DESENLACE DE LA CRISIS eConómica en Argentina y Uruguay (2001-2002): UNA EXPLICACIÓN DESDE LA TEORÍA DE LAS PROSPECTIVAS
}

\author{
Fernando Rosenblatt \\ DOSMIL30, URUGUAY
}

\begin{abstract}
Resumen
Este artículo procura comprender el porqué de la diferente respuesta que Argentina y Uruguay dieron a la última crisis económica de los años 2001 y 2002. ¿Por qué no fue similar la reacción en términos de gobernabilidad democrática? ¿Por qué la crisis argentina "barrió" con la legitimidad del sistema de partidos y en Uruguay no? ¿Por qué en Argentina provocó la renuncia del presidente electo y en Uruguay no? Para responder estas interrogantes, se establece que la disímil ruta seguida en ambos países, en términos de gobernabilidad democrática, se debe a una distinta configuración institucional que se divisa en la larga duración y, más específicamente, en la construcción del modelo económico que hizo eclosión.
\end{abstract}

Abstract

This article tries to understand why there was a different response to the latest economic crises that took place in the years 2001 and 2002 in Argentina and Uruguay. Why was there not a similar reaction in terms of democratic governability? Why did the crises affect the legitimacy of the Argentine party system and not generate the same effect in Uruguay? Why did it force the resignation of the Argentine president and not have the same effect in Uruguay? In order to answer these questions, this article assumes that the different paths followed by both countries during the crises, in terms of democratic governability, can be explained by the different institutional configurations developed through each of their political histories and, more specifically, in the construction of the economic model which collapsed in 2001 and 2002.

PALABRAS CLAVE • Crisis económica • Gobernabilidad • Argentina • Uruguay

\section{INTRODUCCIÓN}

Luego de superada la crisis de la deuda en la llamada "década perdida" y tras haber logrado cierta estabilización en las principales variables macroeconómicas, América Latina retomó un proceso de reformas culminando de gestar un nuevo modelo que guió el crecimiento económico de la región. En materia de política económica apuntaron a una mayor apertura, liberalización y desregulación de las economías de los diferentes países. Se evidenció una orientación prácticamente hegemónica en materia de reformas, registrándose variaciones en el ritmo de aplicación de aquellas. Hacia finales de la década, el modelo económico evidenció ciertas fallas que ocasionaron la interrupción del crecimiento económico, iniciándose así una crisis de importante envergadura. Para el manejo de la misma, los diferentes países siguieron caminos disímiles. 
En el presente artículo se aborda la crisis de dicho modelo económico en Argentina y Uruguay. Las similitudes entre ambos casos se relacionan con procesos de larga duración en las respectivas historias políticas y económicas. Me refiero a la cercanía del establecimiento del régimen poliárquico -más allá de las diferencias en torno a la estabilidad de cada uno- y a las crisis políticas que en la década de 1960 culminarían en la instalación de regímenes autoritarios. La similar trayectoria se completa a través de las respectivas historias económicas, que se vuelve definitivamente "cercana" desde los años 1970, porque fue allí donde se dio comienzo a la instalación del nuevo modelo económico.

Tras la restauración democrática, ambos países tuvieron gobiernos que procuraron emprender, ahora bajo diferentes condiciones institucionales, una profundización de las reformas, siendo ésta la semejanza central que guía el estudio. Con dichas reformas, se procuró liberalizar las economías, principalmente desde el punto de vista comercial, financiero y del peso del Estado en la economía. Los sucesivos gobiernos de Menem y el posterior gobierno de De la Rúa, así como los dos gobiernos de Sanguinetti y el gobierno de Lacalle manifestaron similar intención por seguir dicho proceso de reformas. No obstante, los ritmos seguidos fueron claramente diferentes.

El parecido en el recorrido se evidencia también a partir de los valores que asumieron ciertos indicadores socio-económicos durante el período de estudio¹: Producto Bruto Interno (PBI), Índice de Gini y desempleo. En el momento de desenlace de la última crisis económica -años 2001 y 2002- se observa que estas variables también registraron similares valores.

FIGURA 1: Desempleo: total área urbana (en porcentaje)

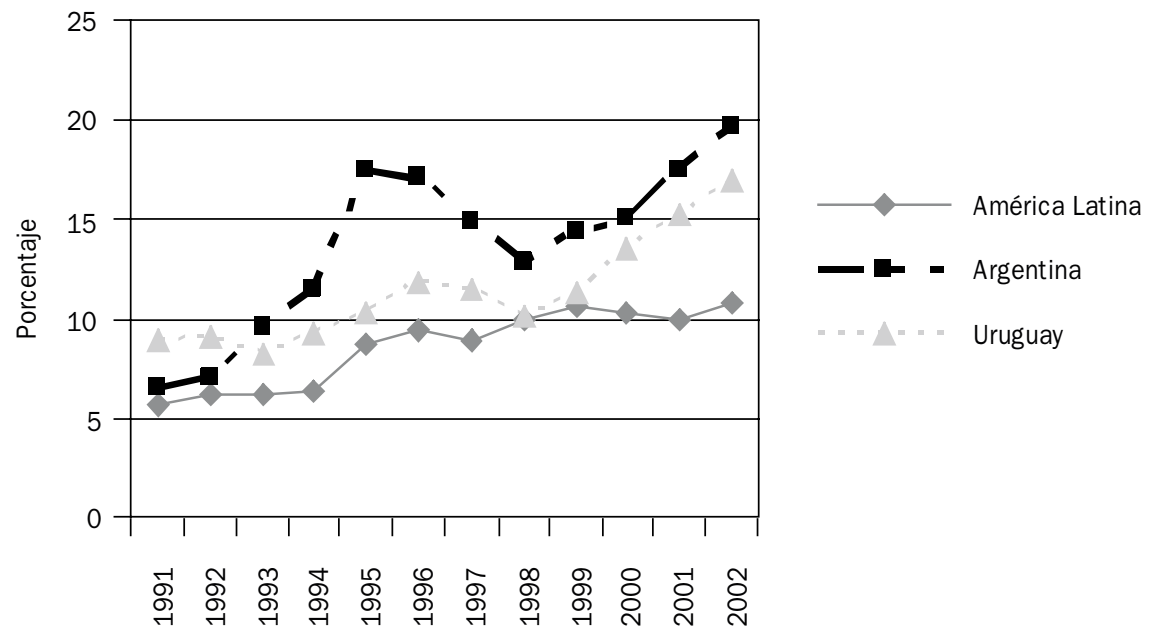

Años

Fuente: Badeinso, www.eclac.org

1 El análisis se inicia en la década de 1990 porque es allí -y no en los primeros gobiernos democráticos tras las dictaduras- donde se asienta definitivamente una orientación hegemónica en las agendas de gobierno. 
FIGURA 2: PBI total a precios constantes de 1995, tasas anuales de variación (en porcentaje)

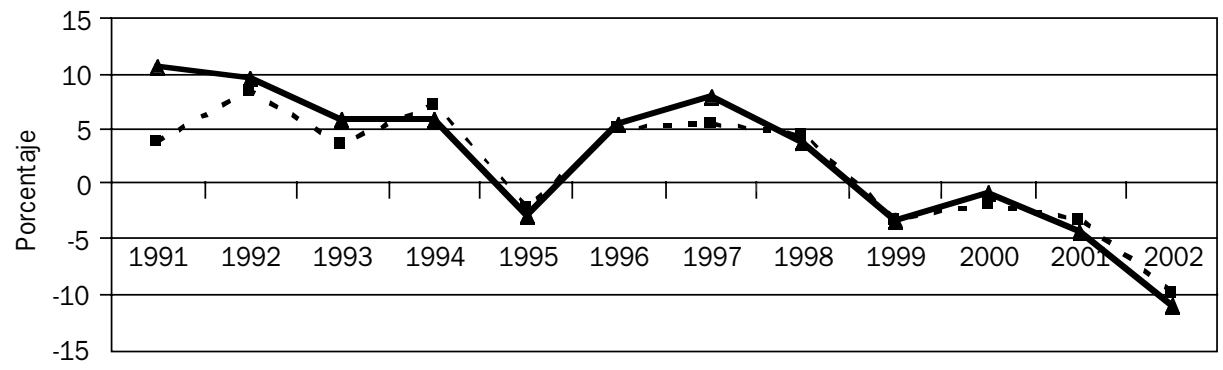

Años

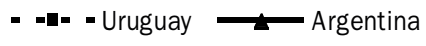

Fuente: Badeinso, www.eclac.org

TABLA 1: Índice de Gini

\begin{tabular}{lccc}
\hline & \multicolumn{3}{c}{ Índice de Gini } \\
\cline { 2 - 4 } & 1998 & 2000 & 2002 \\
\hline Argentina & 0,53 & 0,54 & 0,59 \\
Uruguay & 0,43 & 0,44 & 0,55 \\
\hline
\end{tabular}

Fuente: Badeinso, www.eclac.org

Resulta fundamental recordar que durante el período en estudio, ambos casos pueden ser calificados como democracias, de acuerdo a las mediciones de Freedom House ${ }^{2}$. A su vez, los presidentes que asumieron en 1999 serían políticamente débiles: en Uruguay desde el inicio del mandato y en Argentina en el transcurso del mismo.

Sin embargo, registraron una marcada diferencia en el manejo político de la crisis económica que se sucedió desde finales de los años 1990 y que encuentra su desenlace en los años 2001 y 2002. En este sentido, se intentará señalar cuales son los componentes de la polity-lo político- que explican dicha diferencia.

La hipótesis de este trabajo sugiere que la diferente reacción en términos de gobernabilidad democrática ante una similar coyuntura de crisis económica en Argentina y Uruguay, se explica por la existencia o no de espacios para la cooperación política cuando los actores están ubicados en el domain of losses, o dominio de las pérdidas. Ello, a partir de una diferente articulación institucional. Entonces, la ausencia o no de gobernabilidad democrática para resolver la crisis económica es consecuencia de: a) una ausencia o no de legitimidad y b) inexistencia o no de eficacia para construir cooperación y diálogo: gobierno-oposición y entre poderes. Así, a lo largo del trabajo se pretenderá observar cómo impactó una similar crisis económica sobre la 
gobernabilidad democrática. Para ello, se repasarán cómo se han ido construyendo las instituciones políticas -formales e informales- previo al desenlace de la crisis económica, para explicar así la diferente reacción en términos de gobernabilidad democrática cuando la misma se precipitó. Esto incluirá el estudio de los sistemas de partidos, las relaciones Ejecutivo-Legislativo y el timing en la toma de decisiones. También se incorporará, para la coyuntura de la crisis, el estado de la opinión pública. Estas son las variables que guiarán la comparación, porque permiten dar cuenta de la capacidad de diálogo presente al interior de un sistema político y la presencia o ausencia de legitimidad de los gobernantes, partidos y del sistema democrático.

\section{EL “ESTADO DEL ARTE” Y LA DELIMITACIÓN TEÓRICA DEL PROBLEMA}

En primer lugar, se entiende la Economía Política en un sentido amplio, tal como plantea Grindle: “...He optado por comprender la economía política en un sentido amplio, aludiendo a los esfuerzos por investigar la intersección entre la economía y la política en la elección de políticas [...]" (1999: 2). En este caso, se estudiará el vector que corre de la economía hacia la política: cómo inciden ciertos fenómenos económicos en el proceso político.

En tanto tema de investigación, podríamos decir que se está analizando aquí un problema que se enmarca dentro del fin de la transición entre regímenes políticos y los posteriores dilemas de la restauración democrática. Dichos dilemas tienen que ver con la forma de resolver las cuestiones de gobernabilidad democrática, dentro de lo cual interesa indagar en la articulación del binomio legitimidad/eficacia (Arbós y Giner, 1996). Para ello, la investigación se apoyará en el supuesto que: "El mapa de la segunda transición, como lo fue el de la primera, es un mapa de diversidades" (Lanzaro, 2000: 27).

\section{La elección de la forma de "mirar" el problema}

Se procura una explicación política abarcadora para la comprensión del diferente devenir, en términos de gobernabilidad democrática, de Argentina y Uruguay tras el estallido de la crisis económica. Se intenta resaltar el margen de maniobra de la política, entendida en tanto arena de conflicto, pero también de cooperación y diálogo (Elster, 1998). En este sentido, importará la comunicación entre actores asumiendo que ello otorga legitimidad al rumbo de acción elegido y fomenta un consenso más amplio (Elster, 1998).

Entre las diferentes miradas que abordan la temática de las reformas económicas de los noventa, la de Weyland (2002) es la que se intenta adoptar como enfoque teórico. Weyland se apoya en los hallazgos de la psicología cognitiva y de la Teoría de las Prospectivas (Kahneman y Tversky, 1979), la cual, a su vez, se enmarca dentro de la corriente de la Behavioural Economics. Ésta procura derribar el axioma que señala que los individuos pueden ordenar sus preferencias y, por lo tanto, actuar racionalmente para maximizar su beneficio a la hora de tomar decisiones en situaciones de riesgo. El hallazgo fundamental de la Teoría de las Prospectivas es que los individuos a la hora de emprender cursos de acción se comportan del siguiente modo: “...propensos al riesgo en el dominio de las pérdidas y con aversión al riesgo en el dominio de las ganancias" (Weyland, 2002: 5). 
Sin embargo, dicho autor plantea que los argumentos de la Psicología Cognitiva, trasladados a los estudios de la Ciencia Política, requieren necesariamente de la integración entre "opciones" y "estructura".

Con el institucionalismo, se comparte el registro de las instituciones formales e informales, de los códigos aceptados y las estructuras existentes que funcionan como normas establecidas y que provienen de una determinada tradición histórica. De todos modos, en este estudio de un "tiempo de crisis", no se considerarán como reglas de juego para orientar la acción instrumental de los actores, sino como marco referencial que otorga la capacidad de diálogo -comunicación- frente a un desafío común. A grandes rasgos, entiendo la capacidad de diálogo como la comunicación entre partes, en un marco de equilibrio de poder y mutua -aunque no idéntica-capacidad de incidencia (Elster, 1998).

Ahora bien, el análisis se refiere a un proceso de crisis económica donde se procura comprender el porqué de un diferente manejo de la misma, en dos casos similares. Por lo tanto, la utilización de la perspectiva de Weyland supone que dado que la crisis surgió durante los gobiernos que impulsaron las reformas -incumbents-, estos, si bien ubicados en el dominio de las pérdidas, siguieron un prior option bias -rumbo de acción anteriormente fijado como el favorable- bajo determinado contexto institucional.

En un momento de crisis donde predomina la incertidumbre sobre el futuro lo que está dado es el statu quo cognitivo previo a la crisis -siguiendo estrategias ya conocidas-, donde se destaca el principio de la psicología cognitiva que refiere al sobrepeso de las certezas (Kahneman y Tversky, 1979). Esto supone que a la hora de emprender un curso de acción, tanto los incumbents como el resto de los actores, dan mayor importancia a las certezas. Esto incluye el marco institucional formal e informal concreto así como las percepciones de los actores -gobierno, oposición y ciudadanía-. Ambas dimensiones analíticas serán entendidas en tanto producto de una estructura -construida desde una trayectoria ${ }^{3}$ - que actúan sobre una coyuntura concreta. Estructura y opciones se combinan y traducen en diversas formas de interacción para elaborar decisiones, generando resultados diferentes.

Analizaré entonces cómo el colectivo -gobierno y ciudadanía- construyó sus decisiones no en tanto individuos atomizados preocupados por su propio interés, sino como conjunto que, además de perseguir fines instrumentales, persigue fines sustantivos (Weyland, 2002). Para lo cual observaré las características del intercambio en la toma de decisiones.

Recapitulando, abordaré el estudio de un “tiempo de crisis” económica, donde interesará observar cómo reaccionan las estructuras políticas en una coyuntura determinada donde el riesgo es evidente y los actores se posicionan en el dominio de las pérdidas. Procuro, por último, indagar en los espacios potenciales y existentes para el diálogo (o no obstrucción) entre los diversos componentes del sistema político para resolver el binomio legitimidad/eficacia.

3 El repaso de la trayectoria institucional formal e informal es de corto plazo y se limita al proceso de instalación definitiva de un rumbo de acción para la concertación de un modelo económico. 
FIGURA 3: Marco teórico

FORMALES

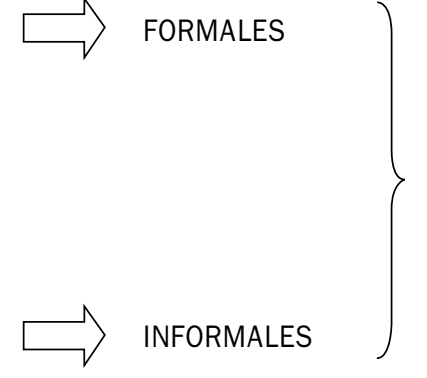

\section{ESTRUCTURA}

(Creadas desde

una trayectoria)<smiles>C1CCC1</smiles>

¿Existe diálogo y

cooperación?

\section{DOMINIO DE LAS PÉRDIDAS}

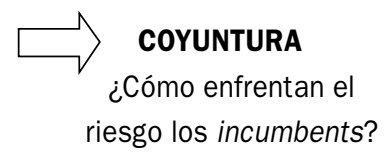

riesgo los incumbents?

\section{Definiciones conceptuales de las dimensiones de análisis}

Las reformas de mercado serán analizadas tal como postula Weyland, es decir, en tanto: “...la dirección del cambio [...]" (2002: 14). Esta dirección del cambio incluye medidas que procuraron reducir el tamaño -o intervención- del Estado en la economía, eliminando regulaciones y restricciones, privatizando empresas públicas y reduciendo la burocracia estatal.

Acompañando las definiciones aceptadas por los economistas y a los efectos de lograr una definición contrastable empíricamente, se considera la existencia de una crisis económica cuando se registra una caída concentrada y profunda del PBI por un período prolongado. En particular, el análisis se enfocará en el desenlace de la crisis que consistió en ambos casos en una crisis financiera: “...una crisis financiera puede ser definida como una salida neta "rápida, masiva y generalizada" de capitales invertidos en activos financieros de un país" (Gervasoni, 2002. 2). A estas definiciones agrego -tal cual lo exige la Teoría de las Prospectivas- la percepción que la ciudadanía se construye en relación a la situación económica. Por lo tanto, se incorpora la evaluación subjetiva del estado de la economía para asumir la existencia de una crisis.

Para estudiar la capacidad de diálogo o de cooperación (no obstrucción) en cada caso, resultan importantes las relaciones institucionales que se tejen entre el Poder Ejecutivo y el Poder Legislativo para la toma de decisiones. Para ello, se utiliza la tipología de Cox y Morgenstern (2002): “...la manera en que los parlamentos juegan su papel es, fundamentalmente, una función de la tasa efectiva de reelección, la estructura de los partidos, el sistema electoral y la constitución" (Morgenstern, 2002: 415). En relación al último de los componentes, Shugart y Carey (1992) distinguen los poderes legislativos y no legislativos de los presidentes. Sin embargo, Malamud (2001) afirma -y comparto- que la distinción entre poderes constitucionales y partidarios realizada por Mainwaring y Shugart (2002) es más apropiada para observar los equilibrios de poder -potencial y real-entre el Ejecutivo y el Legislativo. Entre los poderes constitucionales se distinguen tres de carácter legislativo: de decreto, de veto -total o parcial- e iniciativa legislativa. Esto correspondería a lo que Morgenstern (2002) denomina como constitution. Además, los poderes partidarios son una 
función compuesta por: a) la disciplina del partido del presidente en el Parlamento, b) el número de partidos -fragmentación-y la polarización del sistema.

Si a ello se agregan la composición y los rasgos del sistema de partidos, la tasa de reelección de los legisladores y el sistema electoral, quedaría configurada una particular relación entre el Poder Ejecutivo y el Poder Legislativo ${ }^{4}$.

Para avanzar en el rastreo de los espacios de diálogo, utilizaré los últimos aportes teóricos en materia de sistemas de partidos. La relevancia de un sistema se da por las “...interacciones esquematizadas en la competencia entre partidos. Esta noción sugiere que algunas reglas y ocurrencias regulares en la forma de competir de los partidos son ampliamente observadas [...] e implica también continuidad en sus partes componentes" (Mainwaring y Scully, 1997: 3). En este sentido,

Para que un sistema de partidos democrático se considere institucionalizado, deben cumplirse cuatro condiciones. Primero [...] es la estabilidad en la reglas y en la naturaleza de la competencia entre partidos [...] En segundo lugar, los partidos importantes deben tener raíces más o menos estables en la sociedad [...] Tercero los actores políticos importantes conceden legitimidad al proceso electoral y a los partidos [...] Finalmente las organizaciones partidarias tienen importancia (Mainwaring y Scully, 1997: 4).

Será importante tomar en cuenta los aportes de diversas investigaciones en cuanto a la satisfacción con el funcionamiento de la democracia y la confianza en las instituciones. La pretensión es la de observar cómo el tiempo de crisis incide sobre estas dimensiones que operan como indicadores de la legitimidad del sistema. Las series de tiempo del Latinobarómetro y las consecutivas interpretaciones y análisis de las mismas serán aportes fundamentales para la mirada sobre ambos casos.

Interesan también la forma en que los policymakers asumen los procesos de toma de decisión y de qué manera lo llevan adelante: ¿cuál es el timing en la construcción de decisiones? Se procura observar cómo se modela -a partir de un marco institucional y de la intervención de los actores- el ritmo del policy-making y qué partes intervienen ${ }^{5}$.

\section{DOS PAÍSES, UN MODELO ECONÓMICO}

\section{Argentina: las reformas, una breve mirada al qué y el cómo}

A partir de la elección de Carlos Saúl Menem como presidente, se puede delimitar el inicio de la consolidación de un nuevo modelo económico que se asentaría de manera definitiva, a través de una orientación hegemónica, durante sus dos períodos de gobierno (1989-1999).

4 Vinculado con lo antedicho, Lanzaro (2003) ha avanzado en la categorización de los regímenes de gobierno, como respuesta a la simplificación que se genera al analizar el presidencialismo. Así, podemos encontrar: a) un presidencialismo de mayoría donde "[...] el que gana gobierna [...]" (Lanzaro, 2003: 22) y, b) un presidencialismo pluralista donde "[...] podemos tener relaciones de mayor coordinación-compromisos y coaliciones-que ligan al Ejecutivo con la cámaras legislativas y con otros cuerpos estatales [...]" (Lanzaro, 2003: 23).

5 Para ello, se observará la evolución del índice de reformas construido por Lora (2001). El índice refleja los cambios en cinco áreas de policies: comercial, financiera, impositiva, privatización y legislación laboral. 
Menem logró acceder a la Presidencia de la Nación con una campaña electoral centrada en la relación directa con las masas, con una retórica de “salvación de la patria” (O’Donnell, 1994). Si a esto se agrega la grave situación económica reinante -hiperinflación-y heredada, la preferencia intelectual neoliberal que recorría los centros más importantes de decisión a nivel internacional y el aprendizaje del fracaso de los anteriores shocks heterodoxos, el camino estaba libre para la implementación de medidas de ajuste. Desde una óptica de la Teoría de las Prospectivas, ubicados la élite política y la ciudadanía en el dominio de las pérdidas y sin ser Menem un incumbent, la opción de emprender un camino riesgoso ${ }^{6}$, tanto por parte del gobierno como de la ciudadanía al elegirlo, se explica por la emergencia de una crisis profunda. Weyland dice que: "En suma, crisis profundas vuelven posible el surgimiento de liderazgos carismáticos y neopopulistas y la aplicación de un severo ajuste y la iniciación de reformas estructurales" (Weyland, 2002: 65). Mi precisión del análisis por él efectuado es que la forma de adoptar esas decisiones -no ya el rumbo elegido- se explica no sólo por una coyuntura específica, sino también por una trayectoria institucional formal e informal.

Realizaré ahora un breve repaso de los lineamientos centrales de la política económica que a la postre harían eclosión.

Tras un repunte inflacionario en 1990, en febrero de 1991 asumiría el tercer Ministro de Economía del gobierno de Menem, Domingo Cavallo. A partir de su llegada se comenzaría a gestar el nuevo plan económico que sería el sustento de la estrategia de crecimiento hasta su abandono a comienzos del año 2002: la Ley de Convertibilidad (abril de 1991).

La rápida solución de la hiperinflación y la consecuente estabilización de precios, retroalimentaría el estilo de liderazgo y asignaría confianza para la continuación de políticas económicas reformistas. Así, en una segunda instancia, se avanzó en el plan de privatizaciones, la reforma de la administración y del sistema de seguridad social -introduciendo las Administradoras de Fondos de Jubilaciones y Pensiones (AFJP)-. En suma, se encaró la reducción del rol interventor del Estado.

Entre los principales logros del gobierno menemista durante los primeros años, se puede destacar la estabilidad macroeconómica y el crecimiento económico. Esto fue conseguido a través del aumento en la recaudación tributaria -por el aumento de la actividad económica, la reducción de la inflación y la evasión fiscal-y los ingresos provenientes de las privatizaciones de empresas públicas. Rapoport (2003) sostiene que las mismas se efectuaron para conseguir dicho objetivo y no para mejorar su funcionamiento y la calidad en la prestación de los servicios. En este sentido, Novaro plantea que una de las fórmulas del gobierno menemista fue la ejecución de políticas de “...fácil implementación que produjeran resultados palpables e inmediatos” (2003: 55).

A continuación procuraré desagregar "el cómo", repasando la forma en que fueron construyéndose las decisiones desde el punto de vista político.

6 Tomando decisiones que implicaban altos costos con pocas certezas.

7 Dadas las características del "gobierno solo" de la política argentina y en particular de la presidencia de Raúl Alfonsín, podemos sostener que Menem tenía la posibilidad de reformular la política seguida por el gobierno de quien lo antecedió. En otras palabras, no estaba "atado" al prior option bias del gobierno anterior (Weyland, 2002). 
Jones (2002) resume el funcionamiento exitoso del presidencialismo argentino -hasta 1995- a partir de tres factores ligados entre sí: a) la existencia de un sistema de dos partidos dominantes, b) el nivel elevado de disciplina partidaria y c) un sistema federal que redujo la premisa que, en el presidencialismo, el "ganador se lleva todo". Sin embargo, interesa particularmente lo que Jones (2002) describe como los factores que hicieron que el sistema democrático se viera "opacado". Ellos fueron: a) la limitación del poder y autonomía de las provincias a través del control de flujo de recursos y las amenazas de intervención -en cuatro ocasiones vuelta efectiva-, b) la ausencia de protecciones adecuadas para la rama judicial y c) los poderes legislativos del presidente, en donde se destacó la utilización de decretos de necesidad y urgencia (DNU).

Los poderes legislativos del presidente lo ubican, junto con los poderes partidarios antes descritos, como "potencialmente dominante". En cuanto a lo que se denomina como "decretos delegados" podemos encontrar dos leyes significativas aprobadas en 1989: la 23.696 de la Reforma del Estado y la 23.697 de Emergencia Económica. Por su parte, los DNU fueron utilizados entre 1853 y 1989 en 25 ocasiones -10 bajo el gobierno de Alfonsín-. Sin embargo, entre el 8 de julio de 1989 y el 23 de agosto de 1994 se aplicaron en 336 ocasiones (Fuente: Jones, 2002). Los vetos totales y parciales fueron utilizados en 109 ocasiones durante el primer gobierno de Menem ${ }^{9}$. Sobre todo, fueron aplicados en leyes remitidas al Congreso y que habían sufrido modificaciones que el presidente no consideraba apropiadas (Fuente: Jones, 2002). De este modo, se evidencia una capacidad de legislar sin necesidad de pasar por el Congreso. Ello delinea un panorama que puede ser resumido como de un presidente proactivo y parlamento reactivo ${ }^{10}$.

En cuanto al timing en la toma de decisiones, el período estuvo caracterizado por focos de shock. Esto fue una consecuencia directa del modo en que el régimen de gobierno estuvo articulado en este período. Hubo "reformas intensas" en varios campos entre 1989 y 1993: política monetaria y financiera (Ley de Convertibilidad), política fiscal (con los sucesivos incrementos y generalización del IVA), política comercial (con la reducción de aranceles a la importación), privatizaciones (ENTEL, Aerolíneas Argentinas, sectores de la petroquímica; todos en 1990) y eliminación de control de precios de bienes y servicios (Tomassi, 2004). Se observa entonces que se implementaron políticas de manera veloz en diversas áreas, sin contar con agentes de veto que las frenaran durante la instalación y apogeo del modelo económico.

En suma, el período se caracterizó por la construcción de rumbos de acción no concertados que minaron el accountabillity vertical y horizontal (Novaro, 2003) ${ }^{11}$. En relación a la primera, Menem encarnó la nación, presentándose por encima tanto de partidos como de intereses organizados (O’Donnell, 1994) significando la institucionalización informal de un modelo decisionista de gobierno. En relación a la segunda, la concepción de la relevancia de lo técnicos y el "pasar por encima" del control del Congreso es ejemplo de ello. Novaro afirma que durante los gobiernos menemistas se resolvieron los problemas de gobernabilidad en términos de eficacia, pero no de legitimidad, ya que predominaron los componentes “...delegativos, decisionistas, personalistas, extra o anti institucionales, que colocaban a la democracia argentina frente al peligro de que los 
desequilibrios hiperpresidencialistas se transformaran en un rasgo permanente del orden político" (2003: 52-5). Sin embargo, la marcha de la economía así como las disidencias y conflictos a la interna del PJ durante su segunda presidencia, frenarían la intensidad del proceso de reformas y provocarían la derrota electoral en las legislativas de 1997. Finalmente, provocarían la rotación del partido en el gobierno en las presidenciales de 1999.

\section{Uruguay: las reformas, una breve mirada al qué y el cómo}

La década del noventa se caracterizó por la continuación de muchos elementos que rodearon a la economía uruguaya en las dos décadas anteriores, por la pretensión de instalar un nuevo modelo económico (Antía, 2001 e Instituto de Economía, 2002).

Luis Alberto Lacalle ganó las elecciones en 1989 con un discurso que no se alejó de sus posteriores acciones e intenciones en materia de política económica. Junto con estas elecciones se celebró un plebiscito para asegurar que las jubilaciones y pensiones se indexaran de acuerdo al índice medio de salarios; el apoyo a la propuesta fue de un 72,5\% (Fuente: Moreira 2004). Ello daría la señal al gobierno que no sería tan sencillo llevar a cabo sus pretensiones reformistas. Vale resaltar que Lacalle ganó con el 38,9\% y su fracción obtuvo el 22\% de los votos (Fuente: Lanzaro, 2000).

Si bien Lacalle asumió en un período de crisis, la misma no era tan profunda como en Argentina por lo que la ubicación en el dominio de las pérdidas era más atenuada comparado con este último ${ }^{12}$. De cualquier modo, la reducción de los desequilibrios macroeconómicos fue la principal “obsesión”. Para conseguirla, se persiguió el equilibrio fiscal impulsando diversos ajustes fiscales (1990 y 1995) y se redujo la inversión pública así como los subsidios a las exportaciones (Antía, 2001 e Instituto de Economía, 2002). Se adoptó la política cambiaria como la principal herramienta para conseguir la estabilización de precios aplicando un tipo de cambio fijo con bandas de flotación. El resultado fue una lenta estabilización de precios basada en el tipo de cambio (Antía, 2001).

Con una economía que aparecía finalmente "saneada" se pudo profundizar en las medidas liberalizadoras, intentando ahora llevarlas a otros planos. Vaillant (2003) apunta que desde la restauración democrática se continuó la política comercial aperturista iniciada en 1973, aunque en un principio se enlenteció ${ }^{13}$. En relación al sistema financiero -siguiendo a Antía (2001)- se buscó el saneamiento y el fortalecimiento del mismo, procurando continuar con la idea de Uruguay como "plaza financiera regional”. Ello suponía: “...la admisión del dólar como unidad de cuenta para los contratos internos, la libre movilidad de capitales y divisas, y la permisividad para la instalación de la banca off-shore" (Failache et al., 2003: 7).

Hasta 1998 se logró una considerable expansión económica que fue posible gracias a un importante arribo de capitales extranjeros atraídos en esos años hacia los mercados "emergentes" -por lo tanto, es también aplicable al caso argentino-. Arribaron en una escala que permitía, como señala Finch (1997), contrarrestar el déficit en Cuenta Corriente y generar reservas internacionales.

12 El producto estaba estancado y la inflación llegó al 129\% en 1990 (Fuente: Finch, 1997).

13 Ejemplo de ello es que en un primer momento Lacalle decide aumentar los impuestos a las importaciones y luego, en 1992 los redujo (Vreeland, 2003). 
Por otra parte, los intentos por reducir el papel del Estado como agente económico se vieron mayormente frustrados, por lo que la reforma del mismo avanzó lentamente. Encontró los frenos propios de una sociedad que valoraba la intervención del Estado (Forteza et al., 2003). Esto ha valido reformas constitucionales como la de 1989 y la oposición al proyecto de Ley de Empresas Públicas en diciembre de 1992; 79,1\% votó a favor de la derogación de ciertos artículos (Fuente: Moreira, 2004). Se constata entonces cómo la ciudadanía -y sus distintos canales de expresión- pusieron un freno significativo en determinados aspectos del nuevo modelo económico. Este freno no impidió, sin embargo, que se vendiera el 51\% de las acciones de PLUNA, que la Compañía de Gas se vendiera en su totalidad a GASEBA en 1994, que el BSE perdiera el monopolio de seguros de automóviles, que se otorgaran concesiones para la prestación de servicios en distintas áreas, entre otros.

A su vez, se conformó -en el segundo gobierno de Sanguinetti- un sistema de seguridad social mixto combinando la capitalización individual controlada por las AFAP con el régimen anterior controlado por el BPS (Bergara et al., 2004). Paralelamente, se encaró la reforma de la Administración Central, procurando mejorar su eficiencia y obtener una mayor descentralización de sus funciones.

En relación a "Io político", respecto a las relaciones Ejecutivo-Legislativo, los presidentes electos contaron con importantes poderes legislativos como la iniciativa privativa, la iniciativa presupuestaria, el veto parcial y, por último, la posibilidad de enviar proyectos de Ley de urgente consideración (Fuente: Chasquetti y Moraes, 2000; Bergara et al., 2004). Se habla de "asimetría formal" por la configuración de un presidente institucionalmente fuerte en relación al Poder Legislativo (Chasquetti y Moraes, 2000). Pero se debe tomar en cuenta lo que estos autores denominan como "control político", que surge de los efectos que provoca el sistema electoral. Todo lo cual redundó en presidentes políticamente débiles.

A pesar que se han mantenido a lo largo de la historia política los rasgos propios de un sistema de partidos institucionalizado, es de destacar la consolidación de un tercer partido con posibilidades ciertas de ganar. Con ello, el sistema de partidos se fragmentó en tercios -manteniéndose constante la existencia de fracciones institucionalizadas-. El crecimiento del caudal electoral del Frente Amplio confirmaría el pasaje de un "sistema bipartidista" a un "multipartidismo moderado" -siguiendo a Sartori (1981)-, modificando los ejes de la competencia partidaria. Concomitantemente con el crecimiento del FA, fue decreciendo el apoyo parlamentario del partido ganador (con la excepción de la elección de 1999) y de la fracción del presidente (con la excepción, aunque no muy significativa, de la elección de 1994). De este modo, los presidentes que gobernaron desde la restauración democrática debieron efectuar pactos no sólo dentro de su partido, sino también interpartidarios, para poder llevar adelante sus agendas de gobierno.

Las coaliciones de gobierno -las cuales fueron aumentando su vigor- son un rasgo central de este período, estableciéndose una coordinación que unieron -a través de compromisos- al Poder Ejecutivo y al Poder Legislativo (Lanzaro 2000). Sin embargo, esto sucedía en el marco de una oposición que, como vimos, venía en constante crecimiento. Debe agregarse, además, la elevada tasa de reelección en el legislativo, lo cual redundó en un mayor aprendizaje de la tarea legislativa -profesionalización, en términos de Morgenstern (2002)-y en un mayor poder de influencia ${ }^{14}$. De este modo, se configuró un esquema de fuertes "frenos y contrapesos" y podemos decir enton- 
ces que el Poder Legislativo no ha sido meramente reactivo. Por lo tanto, existió un Coalitional President, workable assembly (Cox y Morgenstern, 2002).

Analizando el timing, podemos destacar el carácter gradual de la implementación del proceso de reformas estructurales. Ello se debe a los constreñimientos derivados de las instituciones formales -presidente con fuertes poderes legislativos, pero en un marco de multipartidismo y fraccionalización partidaria, democracia directa, entre otros- y de las instituciones informales o tradición cívica (coparticipación y necesidad de construir acuerdos). Todo lo cual desembocó en un modelo que se instaló con medidas graduales y que ha procurado evitar el enfrentamiento sin recurrir a las medidas de shock. En suma, se siguió una "dirección del cambio" similar en Argentina y Uruguay, pero con ritmos diferentes.

\section{EL DESENLACE DE UNA CRISIS CON DOS RUTAS}

En Argentina y Uruguay, los éxitos en el plano económico bajo los gobiernos de Menem en el primero y de Lacalle y Sanguinetti en el segundo demostrarían ser efímeros. El creciente déficit comercial fue financiado con ingreso de capitales en un marco de confianza. Pero desde 1995 el ingreso de capitales se iría reduciendo por la desconfianza creciente en los mercados emergentes -por el "efecto tequila", la crisis asiática en 1997 y la moratoria rusa en 1998- minando el equilibrio en la Balanza de Pagos y la factibilidad del sostenimiento de las respectivas políticas cambiarias. El fin de la coyuntura favorable a nivel internacional estaría también dado por el fin de la renegociación de la deuda en el marco del Plan Brady, el fin del ingreso de capitales por concepto de privatizaciones -en Argentina- y la decisión de la Reserva Federal de EE.UU. de incrementar la tasa de interés (febrero de 1994). A todo esto, debemos sumar la pérdida de competitividad con Brasil tras la devaluación del real en 1999 siendo Brasil y la caída de los precios de los bienes exportados (Damill, Frenkel, Rapetti, 2005; Porto, 2002; Failache et al., 2003).

En Uruguay se puede agregar la recesión que sufrió Argentina, lo cual tuvo un impacto determinante sobre el sector turismo y la demanda de bienes de quien era, junto con Brasil, el principal comprador de Uruguay (Instituto de Economía, 2003). Por último, la epidemia de la aftosa que implicó el cierre de mercados para la carne uruguaya.

Diversas medidas fueron llevadas adelante para corregir los desequilibrios macroeconómicos. En Argentina, a fines del año 2000 se concretó un paquete de ayuda financiera conocido como "el blindaje". En este mismo sentido, el 10 de julio del año 2001 el ministro Cavallo anunció el decreto de "déficit cero". A su vez, el 3 de junio de 2001 se consiguió un canje voluntario de deuda en manos de acreedores privados conocido como el "megancanje", el cual se realizó con tasas de interés más elevadas (Damill, Frenkel, Rapetti, 2005). Vitelli (2002) apunta que con esta medida se incrementaron las expectativas de inevitabilidad de la cesación de pagos por la desconfianza que generaron los mayores rendimientos ofrecidos, lo que se tradujo en un incremento del riesgo país ${ }^{15}$. El FMI, dados el incumplimiento de la meta fiscal y la negativa 
valoración de algunas medidas, decidió no desembolsar los montos comprometidos para el mes de diciembre (Godio, 2002).

Todo lo mencionado supuso una crisis en el sistema bancario; el 8 de noviembre los ahorristas retiraron de aquel \$ 1.300 millones (Fuente: Godio, 2002). Vitelli plantea que: “...la combinatoria [...] entre la casi total dolarización de los depósitos promovida por la autoridad monetaria y la inexistencia de un prestamista en última instancia determinaron la incapacidad de cumplimiento de los contratos financieros" (2002: 22). Los retiros fueron ininterrumpidos desde julio de 2001 hasta la imposición del "corralito" el 1 de diciembre (Damill, Frenkel, Rapetti, 2005) ${ }^{16}$.

En suma, la apertura financiera y el endeudamiento acelerado bajo la convertibilidad derivarían en fuga de capitales, crisis cambiaria y financiera, declaración unilateral de la cesación de pagos de la deuda pública externa e interna - default-y el abandono del Plan de Convertibilidad (Damill, Frenkel y Rapetti, 2005).

Entretanto, en Uruguay: “La crisis se profundizó ya en los primeros meses del año [2002], cuando los efectos de la acentuación de la crisis argentina golpearon a la economía nacional, debilitada desde el punto de vista productivo, fiscal y financiero" (Failache et al., 2003: 15). ¿Cómo se evidencia la profundización de la crisis? a) Por la pérdida del investment grade a partir del 13 de febrero de 2002, b) por el aumento de la prima de "riesgo país"17 y c) por último, por un mayor deterioro de las finanzas públicas por el incremento de la deuda pública; endeudamiento que financió los sucesivos déficit fiscales (Failache et al., 2003) ${ }^{18}$.

Entre las causas apuntadas para explicar la crisis bancaria -además de las que previamente subrayé como indicadores de la profundización de la crisis- se pueden destacar: a) la existencia de una importante proporción de créditos en manos de no residentes -principalmente argentinos-en un contexto plagado de factores externos desestabilizadores (Porto, 2002). b) También el incremento de los problemas de morosidad debido a la elevada dolarización de los créditos concedidos a individuos que cobraban en pesos. c) Los fraudes que no se detectaron a tiempo.

La crisis del sistema bancario, epicentro del "desastre", devino en una crisis de expectativas (Porto, 2002). Esto acarreó el retiro de depósitos en moneda extranjera por US\$ 6.200 millones entre enero y septiembre de 2002 (Fuente: Instituto de Economía, 2003).

En febrero y mayo de 2002, con el objetivo de reducir el déficit fiscal y generar credibilidad (Porto, 2002), se estableció un paquete de medidas conocidas como: Programa de Responsabilidad Fiscal y Ley de Estabilidad Fiscal. Asimismo, se impulsaron decretos que tenían como objetivo la reducción del gasto público (Instituto de Economía, 2003). Se asistió a diversos bancos con problemas de liquidez con la creación -en junio de 2002- del Fondo de Fortalecimiento del Sistema Bancario (Instituto de Economía, 2003). Por último, se adoptaron medidas de protección comercial y se procuró la búsqueda de apoyo internacional. estableció que se podrían retirar \$250 por semana. Todas las demás transacciones quedaban limitadas a cheques, tarjetas de débito, tarjetas de crédito o transferencias electrónicas (Pérez Liñan, 2002).

17 En diciembre de 2001 era de 217 pb y en diciembre de 2002 era de 1870 pb (Fuente: Instituto de Economía, 2003).

18 La deuda bruta del sector público en el año 2002 representaba un 92,4\% del PBI (Fuente: Failache et al., 2003). 
A pesar de estas medidas, la liberalización del tipo de cambio el 20 de junio provocó un aceleramiento de la corrida. Por lo cual, el Fondo de Fortalecimiento del Sistema Bancario sería insuficiente y no lograría detener la "sangría". Esto derivó en que se decretara un feriado bancario el 30 de julio de 2002, luego de haber sido modificado el equipo económico (Instituto de Economía, 2003 y Porto, 2002). Durante dicho feriado se consiguió el apoyo del Departamento del Tesoro de EE.UU. así como del BID, el Banco Mundial y el FMI. Asimismo, se creó por ley -el 4 de agosto- el Fondo de Estabilidad del Sistema Bancario y se decretó la suspensión de actividades de cuatro bancos y una cooperativa de intermediación financiera. Finalmente, el lunes 5 de agosto se levantó el feriado bancario.

\section{LA DIFERENCIA CRUCIAL}

Tras la recuperación democrática de los años ochenta y más nítidamente en los noventa, ambos países se embarcaron en un proceso de reformas que si bien se orientó hacia una misma dirección fue implementado de manera diferente.

Argentina inició el proceso de reformas en un contexto de crisis profunda. Ello, sumado a una frágil acumulación institucional de diálogo entre actores del sistema político, derivó en un proceso de drástico asentamiento del modelo ${ }^{19}$. En el segundo mandato de Menem, comenzaría a acrecentarse el descontento en relación al modelo económico, cuestión que se evidenció en los resultados electorales así como en las disidencias y conflictos que se sucedieron en la interna del PJ.

En agosto de 1997 se creó la Alianza por el Trabajo, la Justicia y la Educación -en adelante, Alianza- para evitar el juego de suma cero dentro de la oposición entre UCR y FrePaSo. En 1997 resultaría vencedora en las elecciones legislativas de mitad de período y el 10 de diciembre de 1999 triunfaría en las elecciones presidenciales. Fernando de la Rúa obtuvo un 48,37\% de los votos (Fuente: Abal Medina y Suárez Cao, 2002) y asumiría como presidente iniciándose una nueva etapa: el gobierno de coalición.

Desde su asunción, las relaciones Ejecutivo-Legislativo tendieron a continuar el equilibrio logrado en la segunda presidencia de Menem y el juego entre partidos políticos tendió a institucionalizarse (Bonvecchi, 2002). Prueba de ello es la capacidad de conformar una coalición entre partidos para alcanzar el gobierno, por primera vez en la historia.

Sin embargo, al incrementarse el deterioro de la situación económica, el esquema político retomó la trayectoria institucional y la tradición cívica de largo plazo. Las relaciones Ejecutivo-Legislativo retomaron la senda del desequilibrio institucional. Al igual que en la instalación del patrón, ello estuvo personificado a partir de la implementación de medidas de shock con el uso de DNU. Domingo Cavallo, arquitecto del Plan de Convertibilidad, fue nombrado ministro de economía en el momento de desenlace de la crisis $^{20}$. Su estrategia fue “...personalizada y decisionista (...)”

Para el año 1989 Argentina presenta un índice de reformas estructurales de 0,366 mientras que en 1993 el índice se elevaría a 0,602. Vale destacar que de todos los países de América del Sur, el único país que vivió un incremento similar fue Perú (Fuente: Lora, 2001).

20 Tras la renuncia de Álvarez, De la Rúa asumió una creciente autonomía respecto a su partido y a la coalición. Reorganizó el gabinete, pero tras fuertes rechazos a la gestión de López Murphy nombró a Cavallo como Ministro de Economía, el 19 de marzo de 2001. 
(Bonvecchi, 2004: 87) ya que la delegación de poderes especiales otorgada por el Parlamento a pedido del propio Cavallo implicó la utilización repetida de DNU.

En cuanto al sistema de partidos, la pauta predominante fue la desintegración de los componentes institucionales que venían madurando. La primera evidencia en este sentido radica en la fragilidad creciente del presidente Fernando De la Rúa. Esto se constata, en primer lugar, por la debilidad e inexperiencia en la construcción de la coalición de gobierno, constituida únicamente para derrotar al menemismo y acceder al poder. Prueba de esto y de la ausencia de un proyecto de gobierno alternativo es el mantenimiento del Plan de Convertibilidad. Además, la misma presentaba problemas de cohesión e institucionalización: “...[la] existencia formal se reducía a una mesa de conducción nacional integrada por [...] cinco dirigentes [...]: Álvarez y Fernandez Meijide, De la Rúa, Alfonsín y Terragno" (Novaro, 2003: 83). Esta cuestión se vincula con una tradición de conformación de coaliciones que procuran derrocar un gobierno y que anuncian la refundación del país.

Además, la creciente debilidad del presidente se observó en la derrota electoral de octubre de 2001. En un contexto de profundización de la crisis económica e inmovilismo político de la Alianza (Novaro, 2003) -exacerbado tras la renuncia del vicepresidente Álvarez-, las elecciones legislativas del 14 de octubre de 2001 significaron un nuevo fracaso para el gobierno. El PJ resultó triunfador en diecisiete de los veinticuatro distritos con un $37,4 \%$ de los votos, manteniendo la mayoría en el Senado y pasando a ser la minoría mayor en Diputados. A su vez, los votos en blanco y no válidos ascendieron a un $21,1 \%$ del total, cifra ésta que era cercana a los votos obtenidos por la Alianza (Fuente: Abal Medina y Suárez Cao, 2002) ${ }^{21}$. El abstencionismo, por su parte, fue del orden del 27,2\% del total de habilitados para sufragar (Fuente: Abal Medina y Suárez Cao, 2002). En total, un $48,3 \%$ de los ciudadanos no optó por ninguna de las ofertas partidarias.

La desintegración de los componentes institucionales del sistema partidario también se observa a partir de la oposición del PJ, el cual en ninguna instancia cooperó. Por lo tanto, a la falta de coordinación dentro de la propia coalición se suma la imposibilidad de negociar con la oposición. A pesar que algunos líderes del PJ lo reclamaran, la profunda división interna impidió que se gestara una estrategia concertada.

A estas fragilidades de las instituciones formales e informales al interior del sistema político se agrega el estado de la opinión pública. La negociación que Menem emprendió a los efectos de obtener la autorización para procurar la reelección así como las acusaciones de corrupción contra su gobierno, comenzarían a erosionar la confianza en el sistema político (Levitsky, 2005). Esta creciente desafección trajo aparejado que la satisfacción con el funcionamiento de la democracia pasara de un $46 \%$ en el año 2000 a un $20 \%$ en el año 2001, llegando incluso a un $8 \%$ en el año $2002^{22}$. A su vez, en el año 2000 un $16,1 \%$ de los argentinos confiaba en los partidos políticos, en el año 2001 esa cifra llegaría al 12,2\% y a un 4,7\% en 2002. (Fuente: www. latinobarometro.org). Todo lo cual se complementa con el hecho que en el año 2000, un 10,2\% de los encuestados respondió que no votaría por ningún partido político mientras que en el

21 En Capital Federal y en Santa Fe el "voto bronca" -votos anulados y en blanco- superó el desempeño de todos los partidos (Fuente: La Nación, 15 de octubre, 2001).

22 Incluí el año 2002, porque la medición del año anterior fue previa a la crisis. 
año 2001 esa cifra se elevó al 42\% y en el año 2002 llegaría al 46\% (Fuente: www.latinobarometro. org ${ }^{23}$. El registro de un elevado porcentaje de "voto bronca" -votos en blanco y anulados- en las elecciones legislativas de octubre de 2001 significó la confirmación de este debilitamiento de las relaciones entre la sociedad y el sistema político ${ }^{24}$. En este sentido, se dice que: "Al reducirse o directamente negarse la complejidad de los problemas que afectan la gestión de gobierno, la insatisfacción con sus resultados termina por ser cargada a la cuenta de la "clase política" [...]" (Novaro, 2002: 348).

La consigna "que se vayan todos" 25 es el reflejo -si bien heterogéneo- de una ciudadanía que no había participado del proceso de construcción del modelo económico, que se sentía frustrada por sus resultados y que no encontraba alternativas luego de los rumbos seguidos por el gobierno de Fernando De la Rúa y por los legisladores que lo apoyaron. En sí, el retorno de estrategias "decisionistas" y el contenido de las mismas dejaron sin alternativa partidaria institucional a la ciudadanía. Todo lo cual, se enmarcó en el gobierno de una coalición que no logró construir una identidad alternativa al asumir el gobierno ${ }^{26}$.

La inestabilidad política creciente y la posterior crisis de gobernabilidad que derivarían en la renuncia del presidente De la Rúa y en la sucesión de efímeros gobernantes hasta la asunción, en enero de 2002, de Eduardo Duhalde, puede explicarse a partir de una trayectoria institucional y una tradición cívica donde no ha existido una acumulación -institucionalización- que volviese posible la cooperación y diálogo entre los componentes del sistema político para contener los efectos de la crisis.

En un marco de instituciones débiles ${ }^{27}$ con déficit republicano (Portantiero citado en Novaro, 2003), el análisis de la coyuntura desde la Teoría de las Prospectivas supone que tanto la élite política como la ciudadanía se encontraban en el dominio de las pérdidas ${ }^{28}$. Los incumbents -gobierno-, siguieron un prior option bias que incluía el mantenimiento del modelo económico (Plan de Convertibilidad). El rumbo seguido no sólo incluyó una estrategia determinada en materia de política económica, sino también "cómo" se llevó adelante. Las "certezas" -instituciones formales e informales construidas ambas a partir de una trayectoria- alentaron la toma de decisiones riesgosas sin diálogo -el "cómo" de largo plazo-. Ello, tanto por parte del gobierno como de la oposición, minando primero la legitimidad y luego la eficacia de las mismas. La espiral fue en

Incluí en esta cifra a quienes respondieron que votarían en blanco/anulado o que no votarían a ningún partido porque de hecho lo que nos interesa es observar la desafección respecto de los partidos políticos (esto se aplicó también para el caso uruguayo).

24 Los votos en blanco y no válidos ascendieron a un $21,1 \%$ del total, cifra ésta que era cercana a los votos obtenidos por la Alianza (Fuente: Abal Medina y Suárez Cao, 2002). En Capital Federal y en Santa Fe el "voto bronca” (votos anulados y en blanco) superó el desempeño de todos los partidos (Fuente: La Nación, 15 de octubre, 2001).

25 Esta consigna comenzó a emerger en los días más violentos de las protestas populares que hacía meses se llevaban adelante (18, 19 y 20 de diciembre de 2001).

26 Las acusaciones de corrupción, la aplicación de estrategias decisionistas, la designación de Cavallo como Ministro de Economía sumada a la continuación de la política económica (centrada en el Plan de Convertibilidad), emparentaba a la Alianza con el menemismo.

$27 \quad$ Planteo que existen instituciones débiles desde la mirada que aquí he procurado desarrollar, es decir: instituciones -formales e informales- que fomentan o permiten la cooperación o diálogo político para la búsqueda de fines sustantivos. En este caso, el fin sustantivo era la preservación del binomio legitimidad/eficacia.

28 En el año 2001 un 79,9\% de los encuestados respondió que la situación económica actual del país era mala o muy mala (Fuente: www.latinobarometro.org). 
crecimiento, ya que una vez depuesto el presidente De la Rúa, sus sucesores, ya no atados a una estrategia específica - prior option bias-y en el marco de la crisis, optaron por decisiones riesgosas en materia de política económica como ser el default y posteriormente la devaluación. Por parte de la ciudadanía, la opción por emprender cursos de acción riesgosos -manifestaciones y violencia- se vincula con la fragilidad y ausencia de alternativas institucionales. En suma, por la ausencia de "certezas" legítimas, alternativas.

A pesar que Uruguay había recorrido un proceso más profundo de reformas durante el régimen autoritario, este trabajo se centra en el comportamiento de ambos casos como democracias ${ }^{29}$.

En el transcurso de la década del noventa, las coaliciones con pretensiones reformistas triunfaron en las elecciones. Sin embargo, la propia constitución de coaliciones así como los institutos de la coparticipación con partidos fuertemente institucionalizados obligaron a la constante emergencia de lógicas negociales. Además, los triunfos se sucedieron con márgenes cada vez menores en tanto crecía electoralmente la oposición. Por lo tanto, los frenos se fueron volviendo cada vez más significativos.

El resultado fue, por un lado, la existencia de coaliciones reformistas que emprendieron -algunas con más determinación que otras- un camino en una dirección similar al seguido por Argentina. Por otro, dado lo recién apuntando en relación al grado de institucionalización y a la no existencia de una crisis severa, la implantación del modelo económico encontró "frenos" que arribaron desde diversas direcciones. La ciudadanía, la oposición partidaria -FA y luego EP-FA- y ciertos integrantes de las propias coaliciones marcaron el ritmo de este rumbo, vetando incluso componentes centrales de la pretensión reformista.

En 1999 se celebraron elecciones presidenciales y legislativas, las primeras en las cuales se aplicó la reforma constitucional de 1996. Si bien las elecciones de 1994 habían confirmado la división del país en tercios políticos, la novedad en esta elección fue que el EP-FA se transformó en la primera fuerza política con un 40,1\% de los votos (Fuente: Moreira, 2004). No obstante, no logró alcanzar la mayoría absoluta necesaria para acceder a la presidencia en la primera vuelta. Por lo tanto, se celebró un balotaje en donde la coalición blanca y colorada que apoyó la candidatura de Jorge Batlle resultó triunfadora con un $54,1 \%$ de los votos (Fuente: Moreira, 2004). Un dato importante es que en la primera vuelta el partido del presidente electo obtuvo un $32,8 \%$ y su fracción obtuvo el 15,6\%, el porcentaje más bajo desde la restauración de la democracia (Fuente: Moreira, 2004). De este modo, por primera vez en la historia política de Uruguay, el presidente electo no tenía la mayoría de bancas de su partido el cual además, no era la primera minoría en el Poder Legislativo.

El triunfo de Jorge Batlle en las elecciones de 1999 significó el caso más extremo de los constreñimientos antes repasados, convirtiéndose en el presidente políticamente más débil de la historia política uruguaya. De este modo, las pretensiones reformistas se vieron severamente limitadas por el funcionamiento de la coalición, por la presencia de una mayoría de otro partido en 
el Parlamento y por la activación de los institutos de democracia directa. A ello hay que agregar la necesidad de gestionar una crisis que se estaba profundizando.

Desde el punto de vista de las relaciones entre el Poder Ejecutivo y el Poder Legislativo, la gestión de la crisis implicó la continuación de una trayectoria de equilibrios institucionales, ya sea por la debilidad política del presidente en el marco de un sistema de partidos fragmentado o por la presencia de un Parlamento experiente con altas tasas de reelección.

El arribo de Atchugarry al frente de la cartera de Economía -sustituyendo a Bensión- marcaría la necesidad, por parte de un gobierno débil desde el punto de vista político, de negociar las medidas necesarias para hacer frente a la crisis manteniendo la estabilidad política. El presidente Batlle lo expresó claramente: “...los tiempos que vienen son tiempos políticos” (El País, 24/7/2002). A tal punto esto fue así, que a la hora de emprender el viaje a Washington para conseguir el respaldo del Departamento del Tesoro y del FMI y mientras transcurría el feriado bancario, Atchugarry permaneció en el país con el objetivo de negociar la Ley de Estabilidad del Sistema Bancario. Fueron tiempos de comunicación entre ambos poderes, de llamados a sala, de interpelaciones y negociación. En Argentina, la asunción de Cavallo como Ministro de Economía bajo la misma circunstancia de crisis severa, es prueba de la fragilidad de la coalición, de la autonomía que De la Rúa persiguió respecto de su propio partido y de la anulación de la opción "política" -de cooperación- para enfrentar la crisis.

En lo que refiere al sistema de partidos y a los rasgos institucionales del mismo, la experiencia de diálogo entre sus componentes tradicionales -PN y PC- lo ejemplifica la permanencia de todos los sectores que conformaban la coalición durante los meses más severos de la crisis.

Por otro lado, resulta imprescindible el repaso del comportamiento del EP-FA así como los mensajes transmitidos por sus líderes durante aquellos días. Desde ya varios lustros el EP-FA había vivido un proceso de crecimiento electoral. Ello, a su vez, se transformó en una victoria potencial hacia las elecciones de 2004 con lo cual se “....aloja e institucionaliza la oposición al gobierno (...)" (Rilla en Buquet et al., 2002: 37). Ofició como una "válvula de escape" dentro del sistema político institucional, en tanto venía procesando una moderación programática que lo acercaba a los votantes de centro y en tanto venía gestando una identidad propia. Si bien su perfil opositor se fue incrementando a medida que la crisis se profundizaba ${ }^{30}$, su oposición era moderada en tanto no se violentaba la institucionalidad. Por un lado, no se atendieron los reclamos de ciertos sectores -principalmente la corriente de izquierda- para promover la anticipación de las elecciones o fomentar las movilizaciones para deponer al gobierno. En enero, Vázquez señaló que a la izquierda "no le gustan ni promueve" los estallidos sociales (citado en Paolillo, 2004: 61). En el mes de mayo Vázquez dijo: “...si alguien cree que nos vamos a callar, se equivoca [...] si alguien cree que nos vamos a desbocar, también se equivoca” (citado en Paolillo, 2004: 229) ${ }^{31}$.

Por lo tanto, una vez que la crisis se profundizó, el timing, a diferencia de lo ocurrido en Argentina, fue en función de los rasgos recientemente mencionados; predominaron la negociación y el intercambio en la toma de decisiones. 
A esta solidez institucional al interior del sistema político podemos agregar el estado de la opinión pública. La constante participación ciudadana en diversas instancias electorales o de democracia directa, han construido una percepción altamente favorable entre la ciudadanía respecto de la democracia. De este modo, la satisfacción con el funcionamiento de la misma, si bien descendió en esos años, no registró las drásticas variaciones que se observaron para el caso argentino. Mientras que en 1999/2000 un 69\% de los encuestados se manifestó satisfecho con el funcionamiento de la democracia, en el año 2001 descendió a un 55\%, en 2002 a un 53\% y en 2003 la cifra llegaría a un $43 \% 32$. En ningún caso la variación es tan radical como en Argentina, aunque sí se observa un aumento de los "demócratas insatisfechos" (Fuente: www.latinobarometro.org). Por su parte, se registró un descenso de la confianza en los partidos: $37,6 \%$ en 2001, 28,5\% en 2002 y 17,4\% 2003. Sin embargo, el porcentaje de encuestados que manifestó que no votaría por ningún partido osciló entre un 13\% en 2001 y 2002 y un 19\% en 2003 (Fuente: www.latinobarometro.org). De este modo, se observa que no se registraron las variaciones constatadas para el caso argentino y, por ende, en Uruguay no se puede hablar de una desafección respecto del sistema político. A su vez, existía una alternativa política institucional -con identidad propia- con posibilidades ciertas de ganar en las elecciones siguientes, lo cual puede apoyar lo antedicho.

Analizando la coyuntura desde el punto de vista de la Teoría de las Prospectivas, se puede afirmar que tanto la ciudadanía como la élite política se encontraban en el dominio de las pérdidas ${ }^{33}$. Sin embargo, la trayectoria de solidez institucional y la tradición cívica de espacios de diálogo entre actores implicó que si bien la estrategia de la coalición reformista fue la de seguir un rumbo de acción conocido y aceptado en materia de política económica, la forma de hacerlo se vinculó con dicha institucionalidad. En el caso del FA, la cooperación, sin eliminar la alternativa política que dicha fuerza suponía para la ciudadanía -“válvula de escape”-, se personificó en los llamados a la estabilidad. Desde la ciudadanía, el estilo de conducirse también encontró lazos con la institucionalidad antes descrita; esto suponía esperar al próximo acto electoral.

Así, con instituciones sólidas, construidas en la larga duración y con una tradición cívica de diálogo e inclusión a partir de pautas mutuamente respetadas, se explica por qué la crisis económica no redundó en crisis de gobernabilidad. 
TABLA 2: La diferencia crucial

\begin{tabular}{|c|c|c|c|}
\hline $\begin{array}{l}\text { Dimensión } \\
\text { de análisis }\end{array}$ & Componentes & Argentina & Uruguay \\
\hline $\begin{array}{l}\text { I.Dominio de } \\
\text { las pérdidas }\end{array}$ & $\begin{array}{l}\text { ¿Lleva a privilegiar } \\
\text { certezas construidas } \\
\text { en la larga duración? } \\
\text { Incuments adoptan } \\
\text { medidas alternativas }\end{array}$ & $\begin{array}{l}\text { Sí } \\
\text { No }\end{array}$ & $\begin{array}{l}\text { Sí } \\
\text { No }\end{array}$ \\
\hline II.Instituciones & $\begin{array}{l}\text { Sistema de Partidos } \\
\text { Coalición y Relaciones } \\
\text { Ejecutivo-Legislativo } \\
\text { Timing en la toma } \\
\text { de decisiones para } \\
\text { enfrentar la crisis } \\
\text { Relaciones } \\
\text { ciudadanía-tomadores } \\
\text { de decisión }\end{array}$ & $\begin{array}{l}\text { Desinstitucionalización } \\
\text { Coalición minoritaria y } \\
\text { frágil. Poder Legislativo } \\
\text { reactivo y servil } \\
\text { Shock } \rightarrow \text { decisionismo } \\
\text { Desafección }\end{array}$ & $\begin{array}{c}\text { Institucionalización } \\
\text { Coalición mayoritaria y } \\
\text { estable. Comunicación } \\
\text { entre poderes } \\
\text { Gradualismo } \rightarrow \\
\text { “tiempos políticos” } \\
\text { Estabilidad }\end{array}$ \\
\hline \multicolumn{2}{|c|}{ En Suma: } & $\begin{array}{c}\text { No existencia } \\
\text { de espacios de } \\
\text { cooperación y diálogo. } \\
\text { Falta de legitimidad } \\
\text { y eficacia: crisis de } \\
\text { gobernabilidad }\end{array}$ & $\begin{array}{c}\text { Existencia de espacios } \\
\text { de cooperación y } \\
\text { diálogo. Legitimidad } \\
\text { estable del } \\
\text { sistema y diálogo } \\
\text { eficaz: no crisis de } \\
\text { gobernabilidad }\end{array}$ \\
\hline
\end{tabular}

\section{CONCLUSIONES}

El propósito del presente artículo fue aportar un marco general, utilizando variables que permitiesen estudiar, desde una mirada específica sobre un hecho concreto -crisis económica-, los espacios de cooperación política -de comunicación, diálogo y no obstrucción-. La tarea realizada consistió en indagar en el vínculo que se teje entre la economía y la política. En este sentido, partiendo de una similar crisis económica en dos países, se buscó explicar la diferente reacción política en términos de gobernabilidad democrática.

La crisis económica ha sido entendida como un punto en la trayectoria de ambos casos. Se estableció que el diferente impacto de la crisis económica sobre la gobernabilidad democrática (resolución del binomio legitimidad/eficacia) se explica a partir de una diferente articulación de espacios de diálogo entre actores al interior de los respectivos sistemas políticos, construidos a lo largo de las historias políticas de cada país. En este caso la mirada se centró en la trayectoria reciente. La dirección y el patrón instalados fueron los mismos. Pero la diferente conjugación institucional y de pautas de tradición cívica conformó un esquema de espacios reales para el entendimiento que volvieron diferente la reacción de cada país frente a la crisis económica. Una 
hipótesis alternativa podría haber sido que el mayor impacto político de la crisis económica en Argentina pudo deberse a un mayor grado de liberalización de la economía. Sin embargo, esta posibilidad es abarcada por el seguimiento que he realizado al timing en la aplicación del nuevo modelo económico. En este sentido, no resulta contradictoria esta hipótesis alternativa sólo que puede ser abarcada por la que aquí he planteado ${ }^{34}$.

Mientras Argentina cargó con una tradición cívica de luchas entre identidades que no se reconocieron, Uruguay ha recorrido un camino más inclusivo ${ }^{35}$. Concomitantemente, mientras en Argentina el sistema de partidos no ha logrado la institucionalización de identidades no abarcadoras del "todo", en Uruguay es posible afirmar que los partidos políticos han construido identidades claramente reconocibles. Éstas, se conjugaron además con reglas de juego-creadas por los propios partidos- donde el diálogo y el acuerdo sobre aquellas fueron rasgos constantes, aunque con ciertas excepciones.

De todo ello deviene también un vínculo preciso entre poderes de gobierno. En Argentina, la pauta predominante ha sido la de la ausencia de equilibrios. En Uruguay, si bien los presidentes contaron con importantes poderes constitucionales, el esquema que se configuró a partir de otras reglas de juego -configuración del sistema de partidos a partir del régimen electoral- dio cuenta de la necesidad de buscar el acuerdo para desarrollar la agenda.

Por último, los vínculos entre la ciudadanía y los tomadores de decisión maduraron de modo disímil. En Argentina: “....aunque la sociedad ya no formule perentorias demandas tomándole la palabra a la recurrente promesa de gloria, las fallas generalizadas de la cooperación que impiden el comienzo de una salida de crisis transforman en furia un desencanto sin ilusión" (Novaro comp., 2002: 349). En Uruguay, la institucionalización de la participación en diversas instancias democráticas así como la configuración de identidades políticas reconocibles y no excluyentes -en tanto compartieron modos de acción política-, provocó que la ciudadanía encontrara lazos de confianza dentro de la oferta política institucional.

Todo lo mencionado evidencia -al menos en las dimensiones de análisis aquí seleccionadas- la existencia de diferentes espacios -construidos en la trayectoria histórica- para la cooperación y el diálogo. De este modo, enfrentados a una similar crisis y ubicados -tomadores de decisión y ciudadanía- en el dominio de las pérdidas, la reacción frente al riesgo fue diferente. El intercambio y el diálogo aseguraron en un caso el mantenimiento de los mecanismos de gobernabilidad y en otro caso no, ya que predominó la obstrucción a las posibles acciones del gobierno y del sistema político como un todo (más allá de la evaluación que pudiera hacerse sobre los aspectos técnicos del manejo de la crisis). Esto sucedió por la existencia de una diferente articulación tanto institucional como de tradición cívica; las "certezas" eran diferentes. En Argentina, ello derivó en crisis de gobernabilidad donde no sólo se vio afectada la eficacia, sino también la legitimidad. En Uruguay, dicha articulación permitió amortiguar los efectos de una crisis severa, evitando el colapso de la legitimidad y eficacia de las decisiones adoptadas. experiencias reformistas en América Latina y cuál debe ser la nueva agenda en esa materia.

35 Vale advertir que ello no supuso el no reconocimiento de la existencia de espacios de competencia y lucha de intereses. 


\section{REFERENCIAS}

Abal Medina, Juan (h) y Julieta Suárez Cao. 2002. "La competencia partidaria en la Argentina: sus implicancias sobre el régimen democrático". En El asedio a la política. Los partidos latinoamericanos en la era neoliberal, editado por Marcelo Cavarozzi y J. M. Abal Medina. Buenos Aires: Ediciones Homo Sapiens, 163-185.

Antía, Fernando. 2001. "La economía uruguaya desde el restablecimiento de la Democracia, 1985-2000". En El Uruguay del siglo XX: La Economía, editado por Instituto de Economía. Montevideo: Ediciones de la Banda Oriental e Instituto de Economía-FCCEEA-UdelaR, 123-162.

Arbós, Xavier y Salvador Giner. 1996. “La Gobernabilidad”. En Ciudadanía y Democracia en la encrucijada mundial, editado por X. Arbós y S. Giner. Madrid: Siglo XXI de España Editores, 2-20.

Bergara, Mario et al. 2004. Political Institutions, Policymaking Processes and Political Outcomes: The Case of Uruguay. Latin American Research Network, BID.

Bonvecchi, Alejandro. 2002. "Estrategia de supervivencia y disuasión. Los procesos políticos de la política económica después de las reformas estructurales". En El derrumbe político en el ocaso de la convertibilidad, editado por Marcos Novaro. Buenos Aires: Grupo Editorial Norma, 107-193.

Bonvecchi, Alejandro. 2004. “La eficacia de las inconsistencias: teoría y práctica del gobierno de la economía”. En La historia reciente. Argentina en Democracia, editado por Marcos Novaro y Vicente Palermo. Buenos Aires: Edhasa, 75-90.

Buquet, Daniel et al. 2002. Informe de Coyuntura N³: otro país. Montevideo: Ediciones Trilce e ICP-FCS-UdelaR.

Chasquetti, Daniel y Juan Andrés Moraes. 2000. "Parlamento y gobierno en el Uruguay. Hipótesis para una teoría del ciclo político". En La Segunda transición en Uruguay. Gobierno y Partidos en un tiempo de Reformas, editado por Jorge Lanzaro. Montevideo: Fundación de Cultura Universitaria e ICP-UdelaR, 297-337.

Chasquetti, Daniel. 2004. "La oposición en la era de las coaliciones: el desempeño parlamentario del FA (1985-2003)". En La izquierda uruguaya entre la oposición y el gobierno, editado por Jorge Lanzaro. Montevideo: Editorial Fin de Siglo-ICP, 353-382.

Corporación Latinobarómetro: www.latinobarometro.org

Cox, Garry y Scott Morgenstern. 2002. “Latin America reactive assemblies and proactive presidents”. En Legislative Politics in Latin America, editado por S. Morgenstern y Benito Nacif. Cambridge: Cambridge University Press, 446-465.

Damill, Mario, Roberto Frenkel y Martín Rapetti. 2005. “La deuda argentina: historia, default y reestructuración”. Documentos Cedes 16: 2-53.

Diario El País: www.elpais.com.uy

Diario La Nación: www.lanacion.com.ar

Elster, Jon. 1998. La Democracia Deliberativa. España: Gedisa, 13-34 y 235-287.

Failache, César et al. 2003. Comisión sobre diagnóstico de la situación actual del país y lineamientos de salida a la crisis. Montevideo: Facultad de CCEEA-UdelaR.

Finch, Henry. 1997. "Towards the new economic model". Research Paper N²2. Liverpool: Institute of Latin American Studies, University of Liverpool.

Forteza, Álvaro et al. 2003. Understanding Reform, the uruguayan case. Montevideo: Global Development Network, FCSUdelaR.

Freedom House: www.freedomhouse.org

Gervasoni, Carlos. 2002. Crisis política y crisis financiera en el gobierno de la Alianza en la Argentina (1999-2001). Austin: Teresa Lozano Long Institute of Latin American Studies, University of Texas at Austin.

Godio, Julio. 2002. Argentina: en la crisis está la solución. La crisis global desde las elecciones de octubre de 2001 hasta la asunción de Duhalde. Buenos Aires: Editorial Biblos.

Grindle, Merilee. 1999. “In Quest of the Political: The Political Economy of Development Policy Making”. CID Working Paper $N^{\circ}$ 17. Harvard: Center for International Development.

Instituto de Economía. 2002. "Principales objetivos e instrumentos de la política económica aplicada en Uruguay: 19902002". Serie de Notas de Clase, NC1/03. Montevideo: Instituto de Economía-FCCEEA-UdelaR.

Instituto de Economía. 2003. Uruguay 2002-2003: Informe de Coyuntura. Montevideo: Instituto de Economía-FCCEEAUdelaR.

Jones, Mark. 2002. “Una evaluación de la democracia presidencial argentina 1983-1995”. En Presidencialismo y Democracia en América Latina, editado por Scott Mainwaring y Mathew Shugart. Buenos Aires: Paidós Latinoamericana, 213-253.

Kahneman, Daniel y Amos Tversky. 1979. "Prospect Theory: An analysis of decision under risk”. Econometrica 47 (2): 263-291.

Kuczynski, Pedro Pablo y John Williamson (ed.). 2003: After the Washington Consensus: Restarting Growth and Reform in Latin America. Washington DC: Institute for International Economics. 
Lanzaro, Jorge. 2000. “El presidencialismo pluralista en la segunda transición”. En La Segunda transición en Uruguay. Gobierno y Partidos en un tiempo de Reformas, editado por J. Lanzaro. Montevideo: Fundación de Cultura Universitaria e ICP-UdelaR, 19-196.

Lanzaro, Jorge. 2003. “Tipos de presidencialismo y modos de gobierno en América Latina”. En Tipos de presidencialismo y coaliciones políticas en América Latina, editado por J. Lanzaro. Buenos Aires, Argentina: CLACSO, 15-50.

Levitsky, Steven. 2005. "Democratic Survival Amidst Economic Failure". En The Third Wave of Democratization in Latin America: Advances and Setbacks, editado por Scott Mainwaring y Frances Hagopian. Cambridge: Cambridge University Press, 63-89.

Lora, Eduardo. 2001. "Structural Reforms in Latin America: What has been Reformed and How to Measure it". Research Department, BID.

Mainwaring, Scott y Timothy Scully. 1997. "Sistemas de Partidos en América Latina”. En La construcción de Instituciones democráticas, editado por S. Mainwaring y T. Scully. Santiago de Chile: CIEPLAN, 1-28.

Malamud, Andrés. 2001. O presidencialismo na América do Sul: Argentina e Brasil em perspectiva comparada. Lisboa: Centro de Investigação e Estudos de Sociología (CIES-ISCTE).

Moreira, Constanza. 2004. Final de juego. Del bipartidismo tradicional al triunfo de la izquierda en Uruguay. Montevideo: Ediciones Trilce.

Morgenstern, Scott. 2002. "Explaining Legislative Politics in Latin America”. En Legislative Politics in Latin America, editado por S. Morgenstern y Benito Nacif. Cambridge: Cambridge University Press, 413-445.

Mustapic, Ana María. 2002. "Oscillating Relations: President and Congress in Argentina”. En Legislative Politics in Latin America, editado por Scott Morgenstern y Benito Nacif. Cambridge: Cambridge University Press, 23-47.

Novaro, Marcos. 2002. "La Alianza, de la gloria del Ilano a la debacle del gobierno". En El derrumbe político en el ocaso de la convertibilidad, editado por M. Novaro. Buenos Aires: Grupo Editorial Norma, 31-106.

Novaro, Marcos. 2003. "Presidentes, equilibrios institucionales y coaliciones de gobierno en Argentina (1989-2000)". En Tipos de presidencialismo y coaliciones políticas en América Latina, editado por Jorge Lanzaro. Buenos Aires: FLACSO, 51-100.

O’Donnell, Guillermo. 1994. "Democracia Delegativa”. Cuadernos del CLAEH 66: 5-20.

O'Donnell, Guillermo. 2001. "Accountabiliy horizontal: la institucionalización legal de la desconfianza política”. POSTData. Revista de reflexión y análisis político $\mathrm{N}^{\circ} 7$.

Paolillo, Claudio. 2004. Con los días contados. Montevideo: Colección Búsqueda- Editorial Fin de Siglo.

Pérez Liñan, Aníbal. 2002. Argentina and the New Pattern of Political Instability in Latin America. Pittsburgh: Department of Political Science, University of Pittsburgh.

Porto, Luis. 2002. Uruguay 2002. Para entender la crisis bancaria. Montevideo: Ediciones de la Banda Oriental.

Rapoport, Mario. 2003. Historia económica, política y social de la Argentina 1880-2000. Buenos Aires: Ediciones Macchi.

Shugart, Mathew y Scott Mainwaring. 2002. "Presidencialismo y democracia en América Latina: revisión de los términos del debate". En Presidencialismo y Democracia en América Latina, editado por Scott Mainwaring y M. Shugart. Buenos Aires: Paidós, 19-64.

Stiglitz, Joseph. 1998. "Más instrumentos y metas amplias para el desarrollo. Hacia el Consenso Post-Washington". Revista del CLAD. Reforma y Democracia 12 (octubre): 691-722.

Tomassi, Mariano. 2004. Understanding Reform: the Case of Argentina. Buenos Aires: Global Development Network, Universidad de San Andrés.

Vaillant. 2003. "Gobierno, bienestar colectivo e intereses particulares: el caso de la reforma comercial en Uruguay". En Economía Política en Uruguay: instituciones y actores políticos en el proceso económico, editado por Diego Aboal y Juan Andrés Moraes. Montevideo: Trilce, 111-136.

Vitelli, Guillermo. 2002. "Las rupturas de la convertibilidad y del Plan Real: la reiteración de una misma historia”. Revista Ciclos 12 (23): 87-116.

Vreeland, James. 2003. "Buscando condiciones, no dinero: el acuerdo de Uruguay con el FMI en 1990". En Economía Política en Uruguay: instituciones y actores políticos en el proceso económico, editado por Diego Aboal y Juan Andrés Moraes. Montevideo: Trilce, 73-92.

Weyland, Kurt. 2002. The Politics of Market Reform in Fragile Democracies: Argentina, Brazil, Perú and Venezuela. Princeton: Princeton University Press.

Fernando Rosenblatt es Licenciado en Ciencia Política por la Facultad de Ciencias Sociales de la Universidad de la República, Uruguay.

(E-mail: fernandorosenblatt@gmail.com) 
